\section{RETENTION OF INDEXICAL BELIEF AND THE NOTION OF PSYCHOLOGICAL CONTINUITY}

\author{
By Desheng Zong
}

A widely accepted view in the discussion of personal identity is that the notion of psychological continuity expresses a one-many or many-one relation. This belief is unfounded. A notion of psychological continuity expresses a one-many or many-one relation only if it includes, as a constituent, psychological properties whose relation with their bearers is one-many or many-one; but the relation between an indexical psychological state and its bearer when first tokened is not a one-many or many-one relation. It followes that not all types of psuchological continuity may take a one-many or many- one form. This conclusion casts doubt on the Lockean appouch to the take no be ach the issue,

by showing that the notion of psychological continuity Lockeans rely on may not be available.

\section{INTRODUCTION}

Here are three propositions:

I. The identity thesis: identity (including personal identity) is a one-one relation

2. The Lockean claim: personal identity consists of some type of psychological continuity

3. The continuity thesis: psychological continuity is a one-many or many-one relation.

On the face of it, and barring substantial unpacking or interpretation, it seems that one cannot consistently hold all three theses at the same time. For supposing that identity is a one--one relation and the continuity thesis (3) is true, the Lockean claim (2) must be false, since it identifies a one-one relation with something that is one-many or many-one in nature. On the other hand, if the Lockean claim is true, then the continuity thesis must be false, since the Lockean claim is supposed to be a claim about personal identity, which is one--one by the identity thesis (I). Finally, if the continuity thesis (3) and the identity thesis (I) are both true, the Lockean claim (2) is false, since it is impossible for the same relation to be both one-one and one-many. It thus appears that one or more of the trio must be abandoned, or something else must be added, if the inconsistency is to go away.

It is not too far from the truth to say that most if not all of the major positions that have emerged in the area of personal identity in the past sixty years or so are largely the result of various attempts to try to square the apparent inconsistency of the three theses, and these efforts fall broadly into two categories, which may be dubbed 'preservationist' and 'eliminativist'. In the preservationist category one finds views such as the so-called 'psychological continuity view' (advocated chiefly by Sydney Shoemaker) and the 'multiple occupancy theory' (championed by David Lewis and his fellow four-dimensionalists). ${ }^{1}$ The continuity view holds that the tension among the three propositions is resolved by adopting the stipulation that only nonbranching psychological continuity is person-preserving. Multiple occupancy theorists, on the other hand, try to show that there is no inconsistency by adding a fourth thesis, that persons perdure rather than endure. More specifically, on this view, if persons do not exist in their entirety at each temporal point during which they exist, then there is a good explanation of why the identity thesis and the continuity thesis might both be true: wherever you have an $n$-line branching (or fusing) of psychological life, you have $n$ temporal phases of $n$ persons. To put this differently, one sees inconsistency between (I) and (3) only because one thinks that persons have spatial location but no temporal parts, a claim which four-dimensionalists reject.

Not all theorists, however, are keen on preserving all three theses. Those who do not are the eliminativists. The so-called 'animalists' are one party in this camp: they reject the Lockean claim (2) outright, while remaining noncommittal in regard to the other theses, or treating the truth or falsity of these theses as neutral on the personal identity issue. (To be fair to the animalists, their position on the issue of personal identity does not require them to take a stance on the truth of the other two claims.) Reductionists are also unsympathetic about saving all three theses. In their view, the Lockean claim is a claim about a non-issue, because the idea of a person, on this view, is merely the result of a language practice featuring a word that has no metaphysical foundation. They are also of the opinion that the identity thesis is probably true, but is irrelevant. The reductionists do, however, have a reason for preserving the continuity thesis (3), although their reason is quite different from that of the Lockean. They believe that the significance of the continuity thesis has to do with the notion of what matters in survival, not the notion of identity.

${ }^{1}$ See, e.g., S. Shoemaker, 'Realization, Micro-Realization, and Coincidence', Philosophy and Phenomenological Research, 67 (2003), pp. I-23; D.K. Lewis, 'Survival and Identity', in A. Rorty (ed.), The Identities of Persons (California UP, I976), pp. I7-40. 
So far I have mentioned only two approaches towards the three theses and a few examples of each. Enumerating all the views currently debated in the area, however, is not the aim of this paper. My plan is rather to draw the reader's attention to a curious fact about the recent debate about personal identity: of all the parties who have attempted to resolve the apparent inconsistency, none has chosen to question the truth of the continuity thesis (3).

This is both surprising and puzzling. It is no surprise that there is no shortage of attacks on thesis (2), for as long as there have been Lockeans, there have been anti-Lockeans. It is also understandable why some would question the identity thesis (I), both in regard to its claimed truth and to its relevance to personal identity. For example, Derek Parfit and his fellow reductionists have argued that the identity thesis is just irrelevant to the issue of personal identity. But even the preservationists and the eliminativists did not go so far as to question the truth of the continuity thesis.

However, the privileged status which has been given to the continuity thesis is undeserved, and the time has come to give it some serious examination. As far as I know, Bernard William's article 'Personal Identity and Individuation' was the first to give a clear presentation of the continuity thesis, and by doing so ushered in the contemporary phase in the debate about personal identity. ${ }^{2}$ The history of the continuity thesis is a very interesting one; certainly the doctrine can be traced back to as early as, not surprisingly, John Locke himself, and it might well have been a key assumption of his view on personal identity (referred to here as the Lockean claim). But the continuity thesis remained mostly implicit after Locke, and it did not assume a pivotal role in the debate until the publication of Williams' classic. This is not to deny the significance of the role played by David Wiggins' writings on the topic, which employed the notion of amoeba-style fission, the notion which did most to popularize and shape the doctrine.

I am of the view that the continuity thesis is a deeply suspicious philosophical doctrine. I also believe that further progress in this area depends on getting clear about this doctrine, which has held sway over the minds of too many philosophers for too long.

I have developed elsewhere two lines of argument against the continuity thesis ${ }^{3}$ in one, I show that physical discontinuity leads to fundamental change in the character of the first person; in the other, I argue that no current theories of direct reference would support the belief that there could

2 B. Williams, 'Personal Identity and Individuation', in his Problems of the Self (Cambridge UP, I973), pp. I-I8.

${ }^{3}$ Presumably there should be references her

to two publications
by the author, removed in the draft for the sake of anonymity?

(- 2010 The Author Journal compilation $\mathcal{O} 2010$ The Editors of The Philosophical Quarterly be continuity of indexical thoughts when there is bodily discontinuity. The purpose of the current paper is to provide a third line of argument, also based on indexical thought, against the continuity thesis. Together these three arguments constitute a strong case against the continuity thesis.

The argument I develop in this paper may be summed up as follows. There are psychological capacities that are directly in the business of retention of indexical belief, and there are psychological capacities whose normal functioning relies on the availability of such beliefs. But physical discontinuity of any form tends to undermine or disrupt these psychological capacities in their belief retention function. To put this slightly differently, there is at least one type of psychological property, namely, psychological states with indexical content, for which a one--many or many-one relation between the states and their bearers is not possible.

This conclusion casts strong doubt on the plausibility of the continuity thesis, and by so doing, undermines the Lockean claim. Clearly, the Lockean claim and the continuity thesis are different claims, but the Lockean claim assumes the continuity thesis. For suppose the continuity thesis is false (in other words, suppose not all forms of psychological continuity may take a one-many or many-one form). It follows that there could be forms of psychological continuity which are by nature one-one (that is, requiring physical continuity). Barring further argument or further assumptions, the Lockean thesis cannot rule out the possibility that the type of psychological continuity it takes personal identity to consist in is not of the one-one type. A Lockean who cannot rule this out is in no position to claim that this theory of personal identity is different from one which takes it to consist in physical continuity. This shows that a commitment to the truth of the continuity thesis is an essential part of the Lockean claim.

This commitment is also its downfall if it can be shown that at least one particular type of psychological continuity which the Lockean must admit is of the one-one type. In $\S \S I I I-V$ I shall show that any replacement of a normal psychological capacity responsible for retention of indexical belief with a psychological quasi-capacity causes discontinuity of this kind of belief. I shall conclude by pointing out the extent of the damage this finding is likely to have on the Lockean view of personal identity.

\section{THE B-RELATION AND THE CONTINUITY THESIS}

Psychological continuity is a relation. But nothing can be psychologically continuous with anything, including itself, just like that and not in virtue of something else. In other words, psychological continuity is a relation made 
up of other things, more specifically, particular relations between psychological properties (states, events, processes, etc.) and their bearers (the physical systems which embody them), such as the relations between amiability and the amiable person, belief and the believer, intention and the person intending, pain and the person in pain, and so forth.

Most agree that if an animal possesses any psychological property, it must have other psychological properties as well. It is, after all, highly unlikely that an animal would come equipped with just one single psychological property but no others. For example, it is unlikely that there could be an animal equipped with the cognitive capacity of belief but not a capacity which makes use of the belief. This is not a fact about psychological properties themselves but one about the nature of creatures that have them.

I shall call the relation between a psychological property and its bearer the 'B-relation' (short for 'bearer relation'). What is the nature of the B-relation? Given the multiplicity requirement (as I shall call it), it is quite possible that not all B-relations take a one-many form. Furthermore, whether a psychological property is capable of standing in a B-relation only to the original bearer or to more than one bearer is a matter to be determined by the nature of the property and the conditions required if a creature is to have it.

What this means is that a conclusion about the nature of the B-relation in one case should not be taken in itself as a sufficient ground for its application to another case. The point is easily appreciated in the case of psychological properties belonging to different categories, e.g., personality traits and qualitative experiential states, states with a mind-to-world direction of fit and states with a world-to-mind direction of fit, states with descriptive content and states featuring indexical content, and so on. The same is true of psychological properties within certain general categories, such as beliefs. Although both 'All politicians are crooks' and 'That man over there is a crook' are both beliefs, the two are quite different. The former is descriptive and the latter indexical; one has a satisfaction type of truth-condition, the other a de re one. ${ }^{4}$ There is also a difference between the conditions required of creatures who can be said to have them. While anything that possesses the general concepts which make up the descriptive belief is in a position to have the general belief, only those that stand in a de re relation to the object of the belief can have the indexical belief.

Notwithstanding the complexity of the situation regarding the B-relation, philosophers participating in the debate about personal identity in recent

${ }^{4}$ In this paper I use the phrase 'indexical beliefs' to cover both beliefs whose ascription typically makes use of pure indexicals such as 'I', 'you', 'now', and beliefs whose ascription features demonstratives such as 'this', 'that', 'here' and 'there'. decades write as if psychological states are all the same when it comes to the B-relation. In particular, they seem to think that all psychological properties, from dispositions such as personality and faculties such as perception and memory to individual psychological states with intentional content, are such that their B-relation with their bearer may always take a one--many or many-one form. These beliefs are certainly unsupported. The time has come for a more serious look at these popular beliefs than they have received so far.

\section{PERCEPTION, QUASI-PERCEPTION AND RETENTION OF INDEXICAL BELIEFS}

If I can perceive an object, I am in a position to form a demonstrative concept of it. If I have a demonstrative concept of the object, I am in a position to form an indexical belief about it. Thus if I can see a bird, I am in a position to form the belief 'That bird is F'; if I am hearing the sound of a bugle, I can form the belief 'That bugle sound is G'.

But perception does more than constitute a ground for acquisition of indexical beliefs: it also constitutes a ground for the retention of such beliefs. To continue the examples given above, if I noticed the bird at time $t_{1}$, and formed the belief 'That bird is F' on that basis, then assuming I kept the bird in view from $t_{1}$ to $t_{2}$, I must be said to have retained the belief in that time frame, and would be justified if I said that I did. ${ }^{5}$ This simple fact about the formation and retention of indexical belief in the case of perception has implications for the issue of psychological continuity. Any period in the life of a creature must be such that if the creature is able to form on a perceptual basis an indexical belief at the beginning of the period and retain it on the same ground until the end of that period, the creature's life in that period is psychologically related as far as that indexical belief is concerned.

This is of course what happens in the case of normal perception, but I shall now introduce the notion of quasi-perception, henceforth, for short, ' $q$-perception': $S q$-perceives $o$ if (I) $o$ exists; (2) $S$ has the experience of

${ }^{5}$ Retention of indexical beliefs and continuity of capacities responsible for such beliefs are two different things. As mentioned earlier, the concern of this paper is with the capacities. Retention of indexical thought is a subject in its own right and is not dealt with here. For some of the ground-breaking works on this topic, see D. Kaplan, 'Demonstratives', in J. Almog et al. (eds), Themes from Kaplan (Oxford UP, I989), pp. 48I-563; G. Evans, 'Understanding Dethe Continued Belief', in his The Problem of the Essential $291-321$, J. Penter 'A Problem about the Continued Belief, in his The Problem of the Essential Indexical and Other Essays (Oxford UP, 1993), pp. 69-9o, and Rip Van Winkle and Other Characters', European Review of Analytical Philosophy, 2 (1998), pp. I3-39. But also see S. Prosser, 'Cognitive Dynamics and Indexicals', Mind \& Language, 20 (2005), pp. 369-91. 
seemingly perceiving 0 ; (3) $S$ 's experience of seemingly perceiving 0 is caused by the interaction between a person $\mathcal{T}$ (who may or may not be $S$ ) and 0 ; (4) $S$ is either unaware of this particular feature of the experience, or is aware of it, but is unable to tell whether $S$ and $T$ are identical, or to identify demonstratively the $o$ responsible for the apparent experience of seeing 0 .

To illustrate $q$-perception, suppose devices are set up in the heads of two persons $S$ and $T$ such that every time the auditory apparatus of $T$ is directly stimulated by information from an object $o, S$ undergoes the experience of seemingly hearing a certain type of sound. Let $o$ be the sound of a bugle being played somewhere near $T$ that activates $T$ 's auditory apparatus and leads to $S$ 's seemingly hearing the sound of a bugle. It is easy to see that $q$-perception does not for $S$ constitute a ground for the formation of an indexical belief. This is because $q$-perception as defined above really comes down to three things: the having of some subjective experience, the existence of some object (process, event, etc.), and the lack in $q$-perceivers of knowledge about or of ability to identify the subject whose perceptual apparatus functions as the mediating cause between the object and the experience. Given this, it is hard to see how $q$-perceivers can form indexical beliefs based on their $q$-perceptions alone. If $S$ is to have a belief of the form 'This F is G', $S$ must have a demonstrative concept of 'this F'. But part of having a demonstrative concept of an object is that one has the ability to point out the object or to locate it, or knows how to approach it if one has to. But this is exactly something which a creature equipped only with $q$-perception cannot do.

But the reason why $q$-perception has to be rejected as a ground for the formation of indexical beliefs is also a ground for rejecting it as a basis for retention of such beliefs. For example, suppose $S$ first forms an indexical belief based on normal perception at $t_{1}$ (say, 'That bugle sound is $\mathrm{F}$ '), but then is made to undergo at $t_{2}$ a process whereby the perception is replaced by $q$-perception. Through $q$-perception, and whatever are the intermediate steps through which the perceptual information is $q$-delivered to $S$, the sound source keeps generating in $S$ the experience of seemingly hearing the continuous playing of a bugle. This whole affair lasts until $t_{3}$, when the causal link between the sound source and the experience is cut off. In a case like this, we must say that the belief discontinued at $t_{2}$; it discontinued because $S$ lost the ability to identify the object demonstratively, either because $S$ is unaware of the now $q$-nature of the perception, or is unable to locate the sound source. It discontinued because $S$ could not tell if the conscious experience was due to the direct activation of $S$ 's own auditory apparatus by the sound, or by the effect on the auditory apparatus of someone else who was at or near the source of the sound. (The continuity thesis requires that the notion of $q$-perception, and that of $q$-memory as well, are conceptually coherent; thus doubt about these cannot be used to undermine my arguments in this and the next section.)

What I have shown is that the retention of indexical beliefs through perception is possible only as long as the bearer of the perceptual ability responsible for the formation of an indexical belief is the bearer of the same perceptual ability as kept track of the perceptual object until a later time. Retention of indexical beliefs cannot tolerate physical discontinuity in bearers. In other words, the B-relation in the case of indexical beliefs formed and retained on perceptual basis can only take a one--one form.

\section{MEMORY, $O$-MEMORY AND RETENTION OF INDEXICAL BELIEFS}

The ability to keep track perceptually of an object about which one has an indexical belief is but one of several ways we have for the retention of such beliefs. But belief retention by perceptually keeping track of the object has its limitations. When objects have moved, or moved away, or when we have moved, they become perceptually inaccessible. Through perceptually losing the objects, we lose the beliefs themselves. This is where memory becomes handy. Memory makes it possible to retain indexical information, including information in the form of an indexical belief, even when the source of the information is no longer perceptually accessible, and there can be little doubt that accessing indexical information off-line in this way is hugely beneficial to an animal. How memory achieves this is a subject beyond the scope of this paper; to make the discussion in this section more manageable, I shall focus only on memory's role in the retention of a proper part of an indexical belief, i.e., the demonstrative idea of the object of the belief.

What conditions are required to retain a demonstrative idea depend on what a demonstrative idea is. If to have a demonstrative idea is to have an ability to do a certain type of thing (as most writers on this subject agree), then to say that one has retained a demonstrative idea is at least to say that one has retained that ability. I shall call this 'the ability condition'. But a concept is also an entity with a content, and this suggests that content preservation constitutes a second condition for retention of demonstrative concepts. I shall refer to this as 'the content condition'. Perhaps more is required for concept retention, but for my purposes these two conditions will do.

The content condition requires that if I can be said to have retained a demonstrative idea formed at an earlier time on perceptual basis, I should 
be able, on the basis of memory, to entertain thoughts featuring egocentric spatial contents inherited from the perception which caused the memory. For example, if I have a current demonstrative idea of 'that Russian' because I am only a few feet away from him and see him, I am in a position to entertain thoughts about his spatial location relative to me, such as ' $\mathrm{He}$ is sitting over there', 'He has just moved to my left', and so forth. Likewise, if I can be said to have retained the demonstrative idea of 'that Russian', I should be able to entertain thoughts such as 'That Russian was sitting only a few feet away from me', 'He was standing to my left', and so on. Lack of ability to entertain thoughts of this type would strongly suggest that I met no Russians last night, or the encounter left no recollection whatsoever, or all memories of that Russian have been completely lost. In none of the three scenarios can I be said to have satisfied the content condition.

The ability condition suggests that if I can be said to have retained a demonstrative idea of something which I had encountered at some earlier time, then I must have retained all or part of the ability to perform certain tasks. What specific type of task? John Perry (in 'Rip van Winkle') mentions recognition, inference and communication, among others. More illuminating for my purposes is an ability Gibsonians believe defines perception, namely, the 'affordance' of a perceived object or situation. ${ }^{6}$ On this theory, to perceive a ditch, for example, is to perceive its can/cannot-be-jumpedover-ness by me, the perceiver; to perceive some weights in the gym is to perceive their too/not too-heavy-for-me-to-lift-ness, and so forth. Applied to retention of demonstrative ideas, this suggests that one has retained a demonstrative idea of an object only if one has retained the affordance of the object picked up at the time of perception. I can be said to have retained the demonstrative idea of 'That ditch' only if I exhibit a readiness to jump over the ditch when the situation calls for jumping it.

What happens to the formation and the retention of these concepts when memory is replaced by $q$-memory? Certainly the issue of concept formation on the basis of $q$-memory is one worth exploring, but in what follows I shall only focus on the role of $q$-memory in belief retention and I shall not discuss its role in belief formation, mainly for two reasons. First, whether $q$-memory can be a legitimate ground for new beliefs is a subject in its own right and cannot be dealt with here; secondly, if $q$-memory can be shown to constitute a ground for formation of new indexical beliefs and their retention, this would only reveal in terms of psychological continuity something about the

${ }^{6}$ John Campbell's idea of a causally indexical term (e.g., 'too heavy for me to lift') is reminiscent of the Gibsonian notion of affordance, and can be used effectively to illustrate what I here call 'the ability condition'. See J. Campbell, 'The Role of Physical Objects in Spatial Thinking', in N. Eilan et al. (eds), Spatial Representation (Oxford UP, 1993), pp. 82-8. relation between the periods of the individual after fission, not about periods that sit across fission, which is what concerns me here. Following standard practice, I shall say that $S q$-remembers some event $e$ if (I) $S$ has an apparent memory of experiencing $e$; (2) there is someone $X$ who experienced $e$ ( $X$ may or may not be identical with $S$ ); (3) $X$ 's experiencing $e$ is causally responsible for $S$ 's having the apparent memory; and (4) $S$ is either unaware of the $q$-nature of the memory, in which case the memory is a weak $q$-memory, or is aware of it, in the same sense as that in which people 'remember' what has been told them by others about what happened in the past, in which case the memory is a strong $q$-memory. ${ }^{7}$ If $q$-memory is really genuine memory (and only differs from the latter in some inessential aspect), then like memory, it should constitute a ground for the retention of demonstrative ideas. But does it? To answer this question, I need to consider weak and strong $q$-memory separately.

The problems facing the weak $q$-rememberer are two-fold. First, as I said earlier, someone who has a demonstrative idea of an object on a perceptual basis is someone who can entertain thoughts featuring egocentric spatial content inherent to perception. Correspondingly, if I can be said to have retained a demonstrative idea of an object from an earlier perceptual encounter with the object, I should be able to entertain thoughts with this content. But given this status, the weak $q$-rememberer is in no position to think the egocentric content which the $q$-memory has inherited from the perception. Suppose a weak $q$-rememberer $S$ makes a self-ascription of something $S$ apparently remembers, say, ' $I$ remember that he moved to $m y$ left at one point during the party'. If this turns out to be a piece of $q$-memory, the 'I' and 'my' have different meanings. But $S$ is none the less disposed not only to have such thoughts, but also to take the egocentric content to be self-directed and not about someone else. But $q$-rememberers are in no position to think such thoughts or to make such self-ascriptions, because of their ignorance about the identity mix-up in their thoughts. So $S$ fails to meet the content condition.

Weak $q$-rememberers also fail to meet the ability condition. For example, the sighting of a certain weight by an average man in the gym may be a perception of lack of affordance, but it can be a perception of affordance in the case of an unusually strong man. What this means is that if the two men have each formed a demonstrative idea which they would express by 'those weights over there', the ideas are likely to be associated with different behavioural tendencies. For suppose the weaker man had unwittingly

7 (I)-(3) plus the first half of (4) give what Andy Hamilton calls 'weak $q$-memory;' (I)-(3) plus the second half of (4) yield what he calls 'strong $q$-memory'. See A. Hamilton, 'A New Look at Personal Identity', The Philosophical Quarterly, 45 (1995), pp. 332-49; I follow his terminology. 
inherited the memory of the stronger man. If he sees the weights the other man had worked with before, it would be natural for him to feel comfortable with the idea of 'go and give them a lift'. But if he does this, he is in for a big surprise - an indication of his failure to meet the ability condition. Strong $q$-rememberers face a different set of difficulties, the first having to do with their knowledge that not everything they seem to remember is memory. Being aware of that, strong $q$-rememberers realize that they cannot take at face value everything they can apparently remember 'from the inside', and will try to sort things out (if they are rational). It is clear however, that in trying to sort things out they cannot just rely on what they can remember 'from the inside', for as far as what they can remember from the inside goes, everything is the same. More is needed if they are to succeed. Moreover, given the situation, it seems that help could only come from third-person testimonial evidence. Suppose a strong $q$-rememberer $S$ succeeds in the task and can now tell which apparent memories are memories and which are $q$-memories. However, to be able to tell memories from $q$-memories is one thing, to have the ability to retain demonstrative ideas on a $q$-memory basis is quite another. The relation between the person who has a demonstrative idea of an object and the object of which it is a concept is supposed to be direct and unmediated (e.g., the relation between the dog at my feet and my concept of 'This dog', while pointing at it, is an example of unmediated relation); but the relation between me and an object someone has just told me about is not unmediated. This shows that knowledge that one is a $q$-rememberer (plus what one can apparently remember 'from the inside') constitutes no grounds for retention of demonstrative ideas.

Furthermore, even if we assume that there are means by which strong $q$-rememberers can sort out the mess in their memories, all this shows is that since they can now distinguish what they remember from what they $q$-remember, they are in a position to avoid the kind of errors to which weak $q$-rememberers are prone, namely, taking what they $q$-remember as a reason for their continued use of certain demonstrative concepts. In other words, if strong $q$-rememberers manage to satisfy the two conditions for retention of demonstrative ideas, this is because they make claims about concept retention only on the basis of what they remember, not what they $q$-remember.

The formation of indexical beliefs and their subsequent retention constitute one form of psychological connectedness capable of linking periods of one's mental life into one continuous whole, regardless of how significant the continuity might be. What I have just shown is that when memory is replaced by either weak $q$-memory or strong $q$-memory, this particular form of psychological continuity between pre-fission and post-fission periods is bound to be lost. The implication of this conclusion for the continuity thesis could not be clearer. If the relation between indexical beliefs and their bearer is to take a one--many or many-one form, $q$-memory must be capable of effecting post-fission retention of demonstrative ideas formed before fission; but I have shown that this is something $q$-memory cannot do.

\section{INFORMATION CONSUMPTION, O-STATES AND RETENTION OF INDEXICAL BELIEF}

The two bases of belief retention discussed so far are two capacities directly in the business of information acquisition and retention. These capacities acquire and/or retain information directly received from the environment. Investigation of the issue of belief retention will not be complete, however, until psychological processes whose proper functions are information consumption are examined as well. First, it is the requirement of rationality that information collected and stored by an organism is put to use, i.e., serves the aims and purposes of the organism. In any case, animals equipped with information collecting adaptations are typically equipped with psychological processes whose normal functioning makes use of information it has acquired and retained, including, in the case of humans, information in the form of indexical beliefs. It is not unreasonable to assume that if an indexical belief is being used or has been successfully deployed by an informationconsuming psychological process, this results in the retention of the belief (depending on the case, the period of retention may vary).

But there is a second reason why we need to look at psychological processes that are mainly in the business of information consumption. We need to look at the issue of what impact the failure to retain indexical beliefs has on the psychological life of the animal whose beliefs they are. Two action-related faculties are desires and plans. Many of our desires and plans are formed on the basis of indexical beliefs, and the tenacity of the desires and plans - in particular, their satisfaction - typically contributes to retention of the belief that first leads to their formation. Thus if I am struck by the thought 'There is not much hair here!' while examining my own crown in the mirror, and the chill which this sends down my spine leads to a desire to prevent the hair loss, this may lead to the adoption of a plan to buy hairgrowth products. It is not the proper job of desires and plans to retain indexical beliefs, but since the normal functioning of these two faculties typically makes use of indexical beliefs, they indirectly contribute to the longer life-span of these beliefs, typically through making the beliefs their very informational basis. 
One example of cognition-related psychological capacities is file integration. I met a man at a party, we shook hands, and I said to myself 'This man has very sweaty hands'. Later I learn that the man I shook hands with was $\mathrm{Mr} \mathrm{X}$, and so I now know that $\mathrm{Mr} \mathrm{X}$ has sweaty hands. But there is no reason to expect that once I gained this piece of knowledge (that $\mathrm{Mr} \mathrm{X}$ has sweaty hands), my memory of that man as I met him on the occasion wherein the belief was formed would disappear. In fact, information integrated into a more general context often strengthens rather than weakens the memory of it.

What happens to an indexical belief when a normal psychological capacity whose proper functioning relies on indexical facts (or information) is replaced with a $q$-capacity? What, for example, would happen to my desire to have more hair when I undergo fission and the fission offshoots wake up to a hairy head? It seems that the whole matter would depend on whether the content of the psychological state generated by the quasi psychological capacity in question - the content of psychological states which fission offshoots inherit from their fission ancestor - makes sense to the fission offshoots as they find themselves.

In the case of the action-based faculties, for example, if a hairy fission offshoot is unaware of the fission that resulted in his creation, he would find his having a desire for more hair puzzling, since he knows that he has to be blind not to know that he is as hairy as a man could ever want to be; this would leave him with no choice but reject the inherited belief 'I am losing hair' as untrue. But if the belief goes, so does the desire to have more hair (unless he is irrational); and if both the indexical belief and the desire based on it are gone, there is no reason to continue to pursue hair-growth related intentions or plans. There is no need to keep that appointment with the hair specialist, to buy that particular product one had planned to buy, etc. But the problem does not stop here, for if the indexical belief is rejected as untrue and the related desires and plans are dismissed as irrational, there is no need for the mind to continue to invest in the memory resources used for hair-related purposes.

Even if the fission offshoots become aware of the process which resulted in their own creation, that in itself will not help the situation much. Those fission offshoots who happen to be hairy would probably dismiss the desire, because it is irrelevant in a peculiar way: it is a desire to have hair on the earlier head, not the current one. For the fission offshoots who happen to be bald, the inherited desire would still seem to be the wrong desire to have, for if they have a desire for more hair, that would be because of their belief 'This head has little hair', not because of a belief they inherited from their fission ancestor, which is about a different head.
The operation of cognition-based psychological states is equally disrupted when an indexical belief of the fission ancestor becomes the information basis of a psychological process in a fission offshoot. As mentioned earlier, in general, indexical beliefs retained through memory can become the premise of an inference, or the grounds for file integration. So suppose you say to me, pointing at a man sitting two tables off from both of us, 'He is a financial guru'. If I remember this man, I shall be able to make justified inferences at a later time, using what you told me (plus what I see through my own eyes). I could say, for example, 'So that man sitting two tables across is a financial guru. He must be a very smart man.' Suppose I now learn that this man was Mr X. I am now able to join the dots: 'So that man sitting just two tables off from me was Mr X!'. However, the situation changes drastically when memory is replaced by $q$-memory (I shall here skip the case of weak $q$-memory and focus only on strong $q$-memory). In the first place, inferences utilizing indexical beliefs inherited in $q$-memory are no longer justified, for the same reason as that for which certain inferences based on what one has learnt through the descriptions of an eyewitness are not justified. Suppose you are sitting on the wall keeping look-out, and you blurt out as you spot a person coming down the street 'What a scrawny man this is!'. I cannot see the man, but suppose I say to you 'Then he [or "this man"] cannot have eaten for a long time, or he must have some kind of illness'. What I say would be inappropriate if I intended to use it referentially (since there would be nothing for me to be directly referring to). What I said could be appropriate only when the 'he' is used attributively, as meaning 'the man you are looking at' (or 'whoever it is that you are looking at'). My situation is not improved one bit if you, while on the wall, were to start to give me descriptions of 'that scrawny man', like 'He is F; he is G; ...', and if I were then to attempt to make use of 'he' or 'that skinny man' referentially, based on your vivid description.

The situation of strong $q$-rememberers resembles the case I have just described, in that $q$-rememberers merely inherit their $q$-memories from someone else. They are in no position either to use the indexical terms referentially in self-ascription or to communicate to others what they appear to remember, nor are they entitled to say, upon learning more information, such as the names of people they $q$-remember, 'So that man was Mr X!' (or 'So he was Mr X!'). It would of course be an entirely different matter if a $q$-rememberer merely uses the referential term as a disguised description. In that case, the $q$-rememberer's use of a referential term such as 'that man' presents no problem, since it is used attributively only.

This brief survey of information-consuming processes provides a stark picture of the disruption which introduction of $q$-states can cause for the 
proper functioning of processes that typically make use of indexical beliefs. If discontinuity of indexical belief due to $q$-perception and $q$-memory is a form of psychological discontinuity, this disruption represents an equally if not more severe form of psychological discontinuity.

\section{INDEXICAL BELIEF AND PSYCHOLOGICAL CONTINUITY: CONCLUDING REMARKS}

Philosophers who find the notion of psychological continuity interesting do so because they believe that the Lockean claim is basically correct. But as I have shown in this paper, the B-relation between indexical psychological properties and their bearers can only take a one-one form. To put it differently, indexical states cannot survive physical discontinuity.

This conclusion has significant implications for the debate about personal identity. In particular, it shows that the Lockean's belief that there are certain psychological properties upon which the position could always rely for its notion of psychological continuity is largely illusory. We can be more specific about what is not available to the Lockean. In particular, the following are generally unavailable. First, psychological states the ascription of which makes use of the first-person pronoun. Bodily awareness such as proprioception, kinaesthetic sensation, pain, and the more 'cogito-like' types of mental states such as 'I remember ...', 'I judge ...', etc., are good examples. Secondly, psychological states with temporal demonstrative content are unavailable (e.g., the state I am in when I think thoughts such as 'It's now Monday', 'Today is a nice day', etc.). Thirdly, psychological states with spatial demonstrative content are unavailable (e.g., the state I am in when I think the thoughts 'It's hot here', 'It looks foggy over there', etc.). Finally, demonstrative mental states whose content directly involves, or is about, material objects are unavailable (e.g., the psychological state I am in when I think the thoughts 'This ball is too bouncy', or 'I like this guy!').

How serious is the damage to the Lockean approach to the issue of personal identity, which critically relies upon the availability of a suitable notion of psychological continuity? The extent of the damage is best appreciated through a look at what might still remain available to a Lockean. Here are some possibilities not ruled out by the argument of this paper: dispositional psychological properties which have no intentional content (e.g., personality traits), psychological states whose content features proper names (e.g., 'It rains a lot in the Adirondacks', 'Mark Twain had nightmares on his visit to India', etc.), psychological properties with descriptive (or general) content (e.g., beliefs such as 'A tall spy is a spy', 'There was a departmental meeting at r:o0 pm on I April i999', 'The r:30 pm train goes to Baltimore'), and desires, such as 'Not everyone wants to live forever', 'All desire fame', 'You would not want to drink moonshine if you had a good Bourbon'.

The problem with this list is clear: a notion of psychological continuity built with any of these is unable to do the job the Lockean requires it to do. For suppose we construct a notion of psychological continuity featuring contentless dispositional psychological properties (type one above). Clearly, this notion, if used as a criterion of personal identity, fails to do the job, since it is unable to distinguish persons from non-persons. After all, such dispositions are shared by both humans and many non-human animal species. On the other hand, a notion of psychological continuity built with psychological properties with descriptive content provides the Lockean with a notion of psychological continuity suitable only for judging the identity over time of either an all-knowing being, such as God (whose omniscience renders indexical thoughts superfluous), or a creature with the capacity to think only eternally true/false thoughts. In both cases, the notion of psychological continuity is ill suited for the purpose of judging the identity of persons. ${ }^{8}$

Utica College
${ }^{8}$ I would like to thank Judy Crane of Southern Illinois University at Edwardsville and my colleagues Fred Zammiello and Robert Halliday at Utica College for reading an earlier version; I have greatly benefited from their comments. I am also indebted to an anonymous referee for constructive and detailed comments, which helped me to streamline the general argument, and in particular the section on memory's role in belief retention. 